\title{
De los technopaegnia carolingios a la clerecía rabínica medieval. Nuevos horizontes en la literatura medieval a la luz de la poesía comparada
}

\author{
Elena GONZÁLEZ-BLANCO GARCÍA \\ Universidad Nacional de Educación a Distancia \\ egonzalezblanco@flog.uned.es
}

Recibido: 10 de julio de 2010

Aceptado: 7 de febrero de 2011

\section{RESUMEN}

El concepto de «mester de clerecía» se plantea aquí como un fenómeno amplio que se inicia en la poesía mediolatina no cuantitativa, en la que el cómputo silábico se convierte en un factor determinante tras la pérdida de la cantidad de las sílabas. En este trabajo analizaremos dos textos de forma comparativa: un poema latino compuesto en el período carolingio en cuartetas pentadecasilábicas y atribuido a Paulino de Aquilea, que refleja ese estadio inicial de la poesía narrativa medieval «a sílabas contadas», y un poema castellano del siglo XIII en cuaderna vía escrito por un autor judío: las Coplas de Yosef. Ambos textos tienen como base el mismo tema: el relato de José narrado en el Génesis, sin embargo, la formulación del mismo, así como el resultado final son muy diferentes. El análisis contrastivo de estos poemas nos lleva a determinar la ideología que subyace a cada uno de ellos, así como a plantear cuestiones claves en relación al concepto de mester de clerecía, su definición, límites y evolución.

Palabras clave: Historia de José. Mester de clerecía. Cuaderna vía. Paulino de Aquilea. Poesía medieval aljamiada.

GonZÁlez-BlanCo GaRCíA., E., «De los technopaegnia carolingios a la clerecía rabínica medieval.

Nuevos horizontes en la literatura medieval a la luz de la poesía comparada», Cuad. Fil. Clás. Estud. Lat. 31.1 (2011) 69-96.

From the Carolingian technopaegnia to the medieval «clerecía rabínica». New horizons in medieval literature illuminated by comparative poetry

\begin{abstract}
The concept of «mester de clerecía» is exposed here as a broad phenomenon whose origins are in Medieval non-quantitative Latin poetry, in which, after the lost of the vowels quantity, the number of syllables is determining. This work will analyze two texts from a comparative point of view: a Latin poem composed in tetrastichs of pentadecasyllables during the Carolingian period, attributed to Paulin of Aquilea, which reflects the initial status of medieval narrative poetry «a sílabas contadas»; and a Castilian poem composed in the $13^{\text {th }}$ century in «cuaderna vía» written by a Jewish author: the Coplas de Yosef. Both have a common source: the story of Joseph narrated in the book of Genesis. However, the literary procedures used by both authors, as well as the final results are very different. The contrastive analysis of the two texts make us determine the ideology present in each of them and also make us pose key questions related to the concept of «mester de clerecía», its definition, limits and evolution.
\end{abstract}


Keywords: Story of Joseph. Mester de clerecía. Cuaderna vía. Paulinus of Aquilea. Medieval poetry written in Hebrew characters.

GONZÁLEZ-Blanco GARCíA, E., «From the Carolingian technopaegnia to the medieval "clerecía rabínica". New horizons in medieval literature illuminated by comparative poetry», Cuad. Fil. Clás. Estud. Lat. 31.1 (2011) 69-96.

Sumario 1. Introducción. 2. El poema latino: los Versus de Iacob et Ioseph. 2.1. Datación y autoría. 2.2. Transmisión y ediciones. 3. El poema castellano: las Coplas de Yosef. 3.1. Datación y autoría. 3.2. Transmisión y ediciones. 4. La comparación de las Coplas de Joseph con el poema latino Versus de Jacob et Joseph. 4.1. Caracterización del marco y los personajes. 4.2. La trama de la historia. 4.3. El desenlace de la historia. 5. Reflexiones finales. 5.1. Semejanzas entre ambos poemas. 5.2. Diferencias entre ambos poemas. 5.3. Interés del tema. 6. Referencias bibliográficas.

A Luis Girón Negrón, gracias a cuya ayuda y consejos ha sido posible la realización de este artículo

\section{INTRODUCCIÓN ${ }^{1}$}

Los orígenes de la poesía narrativa medieval romance no pueden explicarse sin volver atrás la mirada de las investigaciones hacia los textos mediolatinos. Su métrica se desarrolla durante un período complejo en el que el sistema poético clásico se va paulatinamente sustituyendo por nuevos esquemas en los que los metros cuantitativos se transforman en rítmicos y acentuales, y la cantidad de las sílabas como criterio métrico decae a favor de otros elementos, como el cómputo silábico, el acento y la rima ${ }^{2}$.

La evolución del modelo métrico se encuentra marcada por diferentes hitos. En el período carolingio ya hay numerosos ejemplos de poemas en los que el cómputo silábico, inspirado por los technopaegnia y el manejo artificioso de la sílaba ${ }^{3}$ y aún

${ }^{1}$ Este artículo se publica dentro del marco de la realización del proyecto de I+D del Ministerio de Ciencia e Innovación titulado «Historia de la métrica medieval castellana» (FFI2009-09300), dirigido por el profesor Fernando Gómez Redondo y del proyecto «Creación y desarrollo de una plataforma multimedia para la investigación en Cervantes y su época» (FFI2009-11483), dirigido por el profesor Carlos Alvar.

2 A este respecto, son fundamentales los trabajos de Norberg (2004) en el campo de la métrica latina medieval y de Georges Lote (1973) en lo que respecta al origen de la versificación romance. Los principales problemas sobre este asunto los expuse en una comunicación en el «VI Congreso de la Sociedad de Estudios Latinos (SELAT)» (Baeza [Jaén], 27-30 de mayo): Estado actual del debate sobre el origen latino de las estrofas romances.

${ }^{3}$ Ya entre los poetas carolingios del siglo IX encontramos numerosos poemas compuestos en versos de 14 sílabas, que W. Meyer (1885) intentó, sin éxito, explicar como hexámetros rítmicos. 
de la letra ${ }^{4}$ como elementos poéticos, gana terreno al modelo clásico cuantitativo ${ }^{5}$. Una meta importante se alcanzará en el siglo XII, fecha en que la rima en los finales de verso comienza a generalizarse como un recurso poético. El siglo XIII, por su parte, constituirá un importantísimo eje en la evolución hacia la poesía en lengua romance, pues en esta fecha aparecen las primeras manifestaciones poéticas en lenguas vernáculas, amén de una serie de testimonios bilingües ${ }^{6}$ en los que se observa claramente la continuidad existente entre ambos sistemas.

En la literatura castellana, los primeros testimonios de poesía narrativa se manifiestan bajo el molde de la conocida estrofa de la cuaderna vía o tetrástico monorrimo de alejandrinos. Dicha estrofa no es sino una evolución de la métrica mediolati$\mathrm{na}^{7}$ cuyos ejemplos podemos encontrar en las obras de autores como Gautier de Châtillon ${ }^{8}$, el Primate de Orléans, Hilario, o Pedro Abelardo. Es necesario, sin embargo, retroceder en la cronología para observar que los patrones utilizados por estos autores ya aparecían en poetas aún más antiguos, como Sedulio Scoto, Rabano Mauro, Eugenio Vulgar y los propios himnos mozárabes del período carolingio ${ }^{9}$. En sus poemas encontramos ya varios de los rasgos que, siglos después, definirán las características de nuestro denominado «mester de clerecía» ${ }^{10}$ : las estrofas de verso largo

\footnotetext{
${ }^{4}$ Recuérdense obras como el De laudibus Sanctae Crucis de Rabano Mauro, compuesta sobre matrices aritméticas de letras.

${ }^{5}$ La pregunta clave es, probablemente, qué fue lo que hizo que, una vez perdida la cantidad del verso clásico, se pasara a un sistema en el que el elemento ordenador y clasificador de los nuevos versos fue la pura fórmula matemática de su número de sílabas. La respuesta a esta compleja evolución tenemos que buscarla en la técnica de los llamados technopaegnia, que floreció del afán formalista, mecanicista y sapiencial de la cultura de la Antigüedad Tardía. Es en dicha época cuando los poetas e intelectuales, «buscadores de sabiduría», compusieron auténticas piezas de orfebrería lingüística, utilizando todo tipo de recursos que tenían en sus manos: versos acrósticos, telésticos, preces abecedariae, versos figurados, y otro sinfín de artificios, entre los que hay que considerar la rima en todas sus modalidades, y probablemente también el acento. Para ello, era necesario regularizar el verso que servía de base y una vez establecido, jugar con sus posibles combinaciones, variaciones y expresividad. Esta forma artificiosa de utilizar el lenguaje poético ha sido estudiada, entre otros, por Antonio Alvar (1998).

${ }^{6}$ Sobre estos poemas, véase Zumthor (1960).

${ }^{7}$ Que ya ha perdido su carácter cuantitativo, concediendo especial importancia al cómputo silábico. En ella tenemos que contar con los poemas carolingios ya aludidos, de metro largo variado, además de los conocidos poemas goliárdicos.

${ }^{8}$ Sobre la importancia de este autor como precursor de la forma de la cuaderna vía, véase mi comunicación en el «XIII Congreso Internacional de la Asociación Hispánica de Literatura Medieval (AHLM)» (Valladolid, 15-19 de septiembre): Gautier de Châtillon y la cuaderna vía española y europea.

${ }^{9}$ Como ejemplo tenemos los poemas del códice Vigilano, estudiados, entre otros por Díaz y Díaz (1979) o Romera Castillo (1980).

${ }^{10}$ Como es bien sabido, las reflexiones en torno al fenómeno del mester de clerecía se apoyan en las afirmaciones de la segunda estrofa del Libro de Alexandre, ampliadas con las reflexiones de los propios textos en cuaderna sobre su propia forma poética. Sobre los horizontes del mester de clerecía y sus problemas hemos tratado en nuestro trabajo «Las raíces del mester de clerecía» (González-Blanco 2008), y en «El exordio de los poemas romances en cuaderna vía. Nuevas claves para contextualizar la segunda estrofa del Alexandre» (González-Blanco 2009b), abriendo perspectivas a su concepto y notas definitorias. A este respecto, no podemos olvidar la cita de trabajos clásicos como los de Isabel Uría (en especial su monografía Uría 2000), o mi propio libro sobre la cuaderna vía española en su marco panrománico (González-Blanco 2010), en el que se recoge de forma exhaustiva la bibliografía más reciente en torno a la cuaderna vía castellana y romance. El presente trabajo camina en la misma dirección con un ejemplo extraído de la literatura comparada.
} 
divididas en dos hemistiquios y agrupadas en tetrásticos, el carácter culto de este tipo de composiciones y de sus autores ${ }^{11}$, la métrica de riguroso cómputo silábico y respeto de la dialefa, y su intención didáctica y moralizante hacen que nos encontremos ante un mismo universo poético en el que se repiten y se heredan los mismos moldes, temas y recursos, aunque con variaciones, como veremos.

Esta continuidad es, precisamente, la que queremos tratar hoy aquí a través de dos testimonios que se encuentran en los extremos de esta cadena poética evolutiva. El primero es un poema mediolatino de los comienzos del período carolingio atribuido a Paulino de Aquilea y compuesto en tetrásticos de versos de 15 sílabas (aún sin rima o con rimas esporádicas). El segundo es un poema castellano del siglo XIV o finales del XIII escrito por un autor judío en cuaderna vía, las Coplas de Yosef, que, aunque utiliza el clásico molde berceano, combina y enriquece el conjunto con los conocimientos del corpus de sabiduría rabínica, así como con determinados procedimientos estilísticos y métricos propios de la poesía hebrea ${ }^{12}$, dando como resultado un poema único y muy rico que los investigadores, en muchos casos, no se han puesto de acuerdo en clasificar ${ }^{13}$.

Ambos textos son muy diferentes y es evidente, tras su análisis, que no guardan relación de continuidad entre sí, pues el autor judío no conocía el texto latino. Sin embargo, su comparación nos resulta altamente interesante, dado que son exponentes de un mismo fenómeno: la creación del «mester de clerecía», desde sus orígenes tempranos en la poesía carolingia (el poema latino que nos ocupa), hasta sus manifestaciones romances más diversas (el poema aljamiado que aquí recogemos).

Los dos poemas presentan varios elementos comunes: en primer lugar, el estar compuestos en una de las estrofas más propias de la poesía narrativa medieval: el tetrástico de versos largos, con rigurosa observancia de las sílabas contadas y el respeto de la dialefa; en segundo lugar, el referirse a una temática común de origen bíblico, que servirá a los respectivos autores como fuente, que enriquecerán otros elementos, botón de muestra de su vasta formación cultural; y en tercer lugar, el perseguir una finalidad de tipo didáctico que buscará el aprovechamiento de sus lectores u oyentes como objetivo principal de la composición. No se trata, pues, de un simple caso de poligénesis sino de la muestra de la evolución de la poesía narrativa medie-

\footnotetext{
11 «Clerecía» se entiende en el sentido de hombres cultos, no necesariamente clérigos (aunque lo son, efectivamente, en su mayoría), pero sí con una formación y un conocimiento muy vasto de las fuentes que les permite componer un tipo de obras destinadas a aportar a sus lectores unos conocimientos beneficiosos y didácticos, frente a la poesía lírica, cuya única finalidad sería el puro deleite.

${ }^{12}$ Como ejemplo tenemos las estrofas zejelescas o las rimas en homoioteleuton.

${ }^{13}$ Existe una importante división entre los investigadores que se ocupan del estudio de la cuaderna vía castellana: los que entienden el concepto del «mester de clerecía» en un sentido más restringido y solamente incluyen bajo este marbete los poemas del siglo XIII cercanos al modelo de composición de Gonzalo de Berceo (como Isabel Uría), y los que interpretan el término de forma más amplia e incluyen otros textos castellanos narrativos cuyas formas métricas, cronología o contenido no se ajustan a los cánones berceanos. Los textos compuestos por autores judíos en cuaderna vía castellana, conocidos como «clerecía rabínica» (Díaz-Mas 1993), entre los que se incluye el poema que vamos a analizar, además de otros importantes textos como los Proverbios Morales de Sem Tob de Carrión, no siempre han sido incluidos y estudiados dentro del grupo canónico del mester de clerecía.
} 
val en dos estadios cronológica, lingüística y culturalmente diferentes. A través de la comparación y el análisis contrastivo de ambos textos veremos el tratamiento que ambos ofrecen a un mismo tema en dos culturas, períodos y lenguas diferentes, pero dentro de los extremos del universo común de la poesía medieval narrativa, y con notables diferencias en sus cosmovisiones que plantean no pocos ni pequeños problemas de identificación.

La historia de José, tema de ambos poemas, cuya fuente se encuentra en el primer libro de la Biblia ${ }^{14}$, ha sido objeto de numerosas narraciones en prosa y verso en lenguas vernáculas, que siguen diferentes versiones, combinando los elementos del relato bíblico con multitud de detalles y nuevos episodios extraídos de distintas tradiciones literarias ${ }^{15}$. El problema de la relación entre las diversas composiciones sobre este tema ha interesado siempre a los investigadores. Ejemplo de dicha temprana preocupación es el testimonio de Menéndez y Pelayo en sus Estudios sobre el teatro de Lope de Vega (Menéndez y Pelayo 1949, p.175):

Comprenden Los Trabajos de Jacob la materia de los capítulos XXXVII a XLVII del Génesis, esto es, la historia de José y sus hermanos. El poeta sigue escrupulosamente el texto de la Sagrada Escritura sin intercalar ninguno de los pormenores fabulosos que se añaden en el relato del Corán, base de antiguas versiones castellanas, tales como el Poema de Yúsuf, obra de algún mudéjar del siglo XIII o XIV, y la Leyenda de José, en prosa, debida al ingenio de algún morisco aragonés del siglo XVI y dada recientemente a luz por el Sr. Guillén Robles. Una y otra obra pertenecen el género de las aljamiadas. Las tradiciones coránicas acerca de José se consignan también en la vasta compilación que el Rey Sabio mandó formar con el título de Grande e general Estoria ${ }^{16}$.

Estas palabras son un breve esbozo de la grandísima repercusión que tuvo el texto bíblico de José en las literaturas hispánica, románica y europea; influencia que ha sido analizada recientemente por Girón-Negrón y Minervini (2006) en su espléndida edición del poema medieval castellano titulado las Coplas de Yosef, a la que remitiremos sucesivamente.

El objetivo de nuestro análisis no es presentar un estudio exhaustivo de los textos, pues el profundizar en cuestiones relativas a los manuscritos, variantes textuales o cuestiones lingüísticas daría lugar a un extensísimo estudio en el cual no deseamos adentrarnos ahora. La naturaleza de ambos poemas es, como ya hemos señalado, distinta, así como su métrica, fuentes y estructura ${ }^{17}$.

14 Gen. 37-50.

${ }^{15}$ Sobre la tradición del tema se recoge abundante información en las ediciones de González Llubera (1935), y Girón-Negrón y Minervini (2006).

${ }^{16}$ Advirtamos que Lope también recoge algún que otro dato extrabíblico, como el motivo midráshico del trigo que flota en las aguas del río (Girón-Negrón y Minervini 2006, p.251).

${ }_{17}$ Advirtamos finalmente que, así como las Coplas de Joseph han dado lugar a una importante bibliografía, apenas hay literatura escrita sobre el poema latino titulado Versus de Jacob et Joseph. 


\section{EL POEMA LATINO: LOS VERSUS DE IACOB ET IOSEPH}

\subsection{DATACIÓN Y AUTORÍA}

Los Versus de Iacob et Ioseph se sitúan en torno al siglo VIII en Friuli, Italia ${ }^{18}$. Su autoría se atribuye a Paulino de Aquilea, de quien tan sólo poseemos unos pocos datos, recogidos en su mayoría en el trabajo realizado por Norberg (1979). Señala dicho investigador que la primera alusión a este autor latino aparece en el año 776, en una donación que Carlomagno realiza a un uiro ualde venerabili Paulino artis grammaticae magistro. También de una carta de Alcuino, Norberg extrae la conclusión de que era originario de Italia y un buen conocedor de la lengua latina; que intimó con los círculos cortesanos carolingios y mereció la confianza del rey, que en el año 787 le nombra arzobispo de Friuli. Al parecer, Paulino jugó un papel importante en el trabajo de pacificación de las regiones situadas a este lado de los Alpes, donde la situación era bastante crítica, especialmente en Aquilea, de ahí el título por el cual se le conoce. Sin embargo, carecemos de datos menores sobre sus actividades y formación. Lo único que sabemos con certeza es que falleció en el 802, fecha que recoge el epitafio que en su honor escribió Alcuino.

Entre las obras de Paulino que se nos han conservado destacan en prosa el Libellus sacrosyllabus, compuesto contra los adopcionistas; Contra Felicem, obra en tres volúmenes contra el obispo de Urgel, Félix (uno de los defensores más activos del adopcionismo); y un Liber exhortationis, dedicado a su amigo Eric, marqués de Friuli ${ }^{19}$. La atribución de obras en verso a este autor resulta, sin embargo, mucho más dudosa. Sabemos con certeza que compuso el poema en hexámetros titulado Regula Fidei y varios himnos, a los que los editores han añadido otros que no parecen provenir de la mano del autor. A partir de 1881, fecha en que Dümmler realiza una edición crítica de los textos de Paulino ${ }^{20}$, comienza a despertarse un mayor interés hacia sus obras, incluyéndose así varios de sus textos en los Analecta Hymnica (Dreves y Blume 1886).

El poema objeto de nuestro trabajo no aparece asociado a las obras de Paulino de Aquilea hasta que Wilmart (1922, pp.33-45) realiza un estudio sobre el manuscrito de Autun, en el que el texto se conserva. El investigador publica la segunda parte de un poema sobre Lázaro (métricamente similar al que nos ocu-

\footnotetext{
${ }^{18}$ Datos obtenidos a partir de la base de datos online del Corpus Rhythmorum Musicum [http://www.corimu.unisi.it/] (último acceso 01/04/2011) publicado en Stella (2007). No podemos olvidar tampoco la monografía de este autor sobre la poesía carolingia de tema bíblico (Stella 1993).

${ }^{19}$ El primero que publicó el conjunto de obras de Paulino fue Giovanni Madrisius (1737). Después de esta, las ediciones fueron parciales y de obras sueltas, hasta llegar a la de Dümmler (1896) y a la de Norberg (1979).

${ }^{20}$ De esta pieza dice Dümmler (1896, p.384):

Así aparece este maravilloso ritmo como una pieza paralela a la mucho más bárbara que yo (Dümmler) mismo publiqué en Le moyen âge, pp.7-11, y por vez primera lo tenemos completo. El autor se comporta con una cierta libertad, alejándose un tanto de la secuencia de su fuente, añadiendo algo, como las quejas de Jacob. Omitiendo otras cosas como la historia de la casa de Putifar y esto casi por completo, como puede comprobarse siguiendo las fuentes en las que el autor se ha inspirado (traducción del original alemán por Elena González Blanco).
} 
pa: $8 \mathrm{p}+7 \mathrm{pp}^{21}$, en estrofas de 4 versos), y nuestro texto, titulado como Versus de Jacob et Joseph. Wilmart, al igual que Norberg, señala una serie de semejanzas entre ambos poemas, que le permiten concluir que el texto fue escrito por Paulino de Aquilea $^{22}$, tras analizar el conjunto formado por la métrica ${ }^{23}$, la lengua, y el tipo de adiciones que realizan sobre el texto bíblico que es su fuente.

\subsection{TRANSMISIÓN Y EDICIONES}

El texto latino ha sido transmitido a través de nueve manuscritos, aunque no se encuentra en ninguno de ellos completo ${ }^{24}$. Solamente este dato es ya revelador de la importancia de la que pudo gozar el poema. Los manuscritos son los siguientes: a) Autun, Bibliothèque municipale, 29; b) Berlín, Staatliche Bibliothek, dep., Quart. 676; c) Berna, Burgerbibliothek, 455 (data del siglo X); d) Bruselas, Bibliothèque Royale, 8860-8867 (s. X); e) Fuldensis deperditus, Venanti Fortunati Opera (ed. Christopher Brower); f) Nápoles, Biblioteca Nazionale, IV. G. 68 (s. X); g) París, Bibliothèque Nationale, lat., 1121 (s. IX); h) Verona, Biblioteca Capitolare, 88 (data del 859); i) Verona, Biblioteca Capitolare, 21 (s. X).

Además, ha sido editado en sucesivas ocasiones. Cronológicamente, la primera en su aparición se encuentra en los Monumenta Germaniae Historica (Strecker, Dümmler, Traube y von Winterfeld 1964-1978) ${ }^{25}$. En 1854 Du Méril publica nuevamente el poema en su libro de Poésies Inédites du Moyen Âge (Du Méril 1969, pp.286-29426), siguiendo el manuscrito de Bruselas (al que denomina $B$ ) y con unas breves notas aclaratorias a pie de página sobre las referencias textuales y etimológicas.

Algo más de una década posterior es la edición de 1896 del propio Dümmler (1896, pp.375-384), más completa que la publicada en los Monumenta, pues indica los versículos del Génesis correspondientes a los versos del poema. También ofrece en nota las variantes de cinco de los testimonios (Bruselas: $G$, Berna: $B$, Verona LXXXVIII: $V 1$, Verona XXI: V2, y el fragmento publicado por Schenkel $A^{27}$ ). En el

${ }^{21}$ Esta notación implica que el primer hemistiquio termina siempre por una palabra paroxítona, y el segundo por una proparoxítona. Es la propuesta por Norberg en su edición de la obra.

${ }^{22}$ La autoría de Paulino de los Versus de Lazaro tampoco se halla unánimemente aceptada.

${ }^{23}$ Aunque se percibe un empleo del hiato considerablemente menor en el poema de José que en el de Lázaro, elemento que puede servir para pensar que pudieran ser de dos autores distintos.

${ }^{24}$ Sobre el contenido de los manuscritos se habla con más detalle en el Corpus dei Ritmi Latini (Stella 2007).

25 Según afirma Guscin (1992, p.56), esta es la única edición que presta atención al códice 21 de la Biblioteca Capitular de Verona ( $V 2)$.

${ }^{26}$ Citamos por la reedición de la obra original.

27 En Sitzungsberichte der Philosophisch-Historischen Klasse der Kaiserlichen Akademie der Wissenschaften 9, 1918. También sabemos por él que un fragmento de nuestro texto que estaba en la biblioteca Cheltenhamer antiguamente fue el manuscrito 18908 del monasterio de Reichenau, que data de comienzos del siglo IX (A). Schenkel señala que dicho manuscrito procede de otra mano que la de Reginbert, que escribió el resto. Afirma que lo que está escrito en el folio 4 fue añadido más tarde y contiene de la estrofa 45,3 hasta la 69. Sólo en este manuscrito se recoge lo que en todos los demás faltaba: el final, cuya copia el Dr. Hampe transcribió para el Dr. Dümmler y en ella hay palabras que faltan e incluso en algunos casos líneas completas, que debían de estar ausentes en el manuscrito. 
recopilatorio de Carmina editado por Hagen (1971, pp.84-90), aparece nuevamente un Versus de Jacob et Joseph. En esta ocasión, a diferencia de las anteriores, los versos se encuentran divididos por sus hemistiquios ${ }^{28}$.

La edición más completa que conocemos del poema latino es la realizada por Dag Norberg de las obras de Paulino de Aquilea (Norberg 1979, pp.39-50), que va precedida de un análisis extenso del texto en relación a Paulino, su supuesto autor, y comentarios acerca de algunas de sus obras, especialmente los Versus de Lazaro, poema métricamente emparentado con el nuestro. Junto a la edición del texto, Norberg proporciona un doble aparato crítico, uno con las variantes de los diferentes manuscritos $^{29}$, y otro con los paralelismos del texto latino con los correspondientes pasajes bíblicos. Guscin (1991), por su parte, ha estudiado más recientemente el conjunto de las ediciones existentes, centrándose especialmente en las variantes contenidas en las ocho estanzas del manuscrito de Verona (V2).

\section{EL POEMA CASTELLANO: LAS COPLAS DE YOSEF}

\subsection{DATACIÓN Y AUTORÍA}

Nos encontramos ante un texto compuesto en lengua castellana ${ }^{30}$ por un autor judío, que se ocupa del mismo tema que el poema latino ya descrito, aunque el tratamiento que realiza del mismo es muy diferente, dado que su autor no conocía el poema carolingio al que nos hemos referido.

La fuente principal de este poema es el texto del Génesis, unido a materiales del midrásh hebreo ${ }^{31}$. El texto sigue con fidelidad el orden bíblico, aunque incorpora materiales de otras tradiciones y altera la estructura de algunas de las partes de la narración $^{32}$. El núcleo del relato bíblico consiste en la descripción del personaje de José, hijo de Jacob, amado por su padre y envidiado por sus hermanos. Nuestro poema, sin embargo, es mucho más extenso y recoge varias historias extrabíblicas de influencia midráshica que salpican el conjunto de forma sutil. Entre los principales

\footnotetext{
${ }^{28}$ Esta edición se atiene al manuscrito de Berna, y en nota coloca unas brevísimas enmiendas y aclaraciones.

${ }^{29}$ A los que se refiere como Parisienses 1121: $P$, Berolinensis: $C h$, Bruxellensis 8860: $B$, Bernensis 455 : $B a$, Augustodunensis 29: $A u$, Veronensis LXXXVIII: $V 2$, Veronensis XXI: $V 3$, y Fuldensis: $F$.

${ }^{30}$ Dentro del ámbito de la literatura hispánica, esta historia tiene varios representantes de distinto carácter y época. Además del poema que ahora nos ocupa, el tema de José abarca seis capítulos de la General Estoria de Alfonso X, así como varias leyendas en prosa sobre la figura de José. En el Siglo de Oro el tema goza de gran éxito, manifestado en obras de Carvajal, Lope de Vega, Sor Juana Inés de la Cruz o Calderón de la Barca (Girón-Negrón y Minervini 2006). Asimismo, contamos con un poema morisco en letra aljamiada titulado Poema de Yúçuf cuyos paralelos con nuestra obra son innegables. En el mundo judío el tema de José, cuya inspiración egipcia es unánimemente aceptada por los investigadores, tiene una popularidad extraordinaria también en el ámbito extracanónico (novela de José y Asenet; Testamentos de los doce patriarcas; etc.). Sobre la trascendencia del tema josefino en la literatura española, véase mi artículo (GonzálezBlanco García 2009).

${ }^{31}$ Importante corpus de comentarística rabínica.

${ }^{32}$ Sigue a veces el texto de Biblias romanceadas o hebreas.
} 
episodios de este tipo destaca la ampliación de la historia de José y la esposa de Putifar $^{33}$. Otro ejemplo de estas influencias lo encontramos en el fragmento que enfrenta a los dos hermanos, Judá y José, que se transforma casi en una lucha épica entre ambos. Nuevas inserciones encontramos al final del poema (286-294) donde se narra qué pasó finalmente con Esaú, hermano mayor de Jacob, al que el texto bíblico apenas presta atención tras la muerte de Jacob, motivo al que el poema latino dedica nueve coplas.

Estos episodios no están escogidos al azar, pues, en opinión de Girón y Minervini (2006), se han seleccionado siguiendo una línea moralizante que hunde sus raíces en la literatura pseudo-epigráfica posexílica, y ayudan a perfilar la imagen edificante del patriarca. Aunque las fuentes midráshicas de estos textos son múltiples y en algunos casos difíciles de identificar, lo que parece claro es que el método de composición de la obra consiste en la amplificación de un texto base, bíblico en este caso, por hibridación con otras fuentes cultas. Una de estas fuentes que se pueden reconocer en el poema es la de una crónica hebrea escrita en Toledo hacia 1160, conocida como Sefer ha-Qabbalah («Libro de la Tradición») y escrita por Abraham ibn Dawd. Dicha crónica sirve para documentar la imagen providencialista de José en el judaísmo medieval (Gutwirth 1996). El conocimiento de este tipo de obras, así como de antiguos textos midráshicos y otras fuentes de la antigua narrativa judeo-helenística tuvo lugar gracias a la presencia en nuestra Península de la corte castellana del rey Alfonso X El Sabio, donde el intercambio de materiales e ideas entre cristianos, musulmanes y judíos era constante y continuo.

Además de la temática y atributos formales y lingüísticos que nuestro poema comparte con sus congéneres hispanojudíos, es importante señalar la existencia en él de procedimientos estilísticos de raigambre semítica adaptados a la métrica castellana. Su metro es la cuaderna vía, pero con una variante zejelesca. Cada estrofa consta de tres versos alejandrinos monorrimos y un cuarto con vuelta en Yosef. Se han propuesto disposiciones en octavas de heptasílabos, pero, sea como quiera, lo que es cierto es que esta métrica coincide plenamente con los poemas que hemos considerado como pertenecientes a la cuaderna vía, forma que también presenta el Poema de Yúsuf arábigo-aljamiado. Hay que añadir también que el texto está dotado de rima interna entre los hemistiquios, y es especialmente abundante la presencia de rimas en homoioteleuton, adaptando así las formas hebreas medievales a la poesía castellana. Este elemento, junto con la presencia de la cesura y el esquema zejelesco, es lo que nos hace ver muy clara la relación de la poesía hebrea con el tetrástico monorrimo castellano ${ }^{34}$. En lo que al estilo de la obra respecta, encontramos una enorme sutileza tanto en su composición como en la descripción de contenidos y en sus efectos retó-

\footnotetext{
33 Aunque aparece brevemente mencionada en el texto bíblico, la recreación que de ella se hace en las fuentes extrabíblicas desarrolla enormemente el motivo y lo adorna con diálogos y escenas.

${ }^{34}$ La vuelta de un nombre como Yosef se daba en los piyyutim rabínicos y es típica de otros poemas zejelescos en hebreo, apareciendo sobre todo en las selihot litúrgicos, las oraciones de contrita confesión de los pecados y de ardiente súplica para su perdón.
} 
$\operatorname{ricos}^{35}$. Muchas de las figuras que emplea derivan de la poética hebraica, como los paralelismos estructurales, la figura etimológica o la rima paronomástica, también presentes en los Proverbios Morales de Sem Tob de Carrión.

A pesar de la popularidad de la que desde sus inicios gozó este texto de las $\mathrm{Co}$ plas, nada sabemos de quién pudo ser el autor del mismo ni de dónde procedía. Aunque se ha hablado mucho de sus fuentes y antecedentes judíos y no judíos, así como de su transmisión, lo cierto es que el tema de la autoría continúa siendo un enigma sin resolver. No obstante, parece evidente que el autor de este poema, al igual que sucede con los que en nuestro trabajo venimos analizando, era un estudioso de formación rabínica cuya erudición bíblica y midráshica se hace patente, y que bebe, a su vez, de una riquísima tradición popular que se refleja en su obra.

Como datación, González Llubera (1935) propone la segunda mitad del siglo XIV, dados los caracteres lingüísticos del texto, así como su forma métrica. Los manuscritos conservados son todos posteriores, pero el estudio de la obra permite remontar el original al período correspondiente al resto de textos de la cuaderna vía. Eleazar Gutwirth, en su estudio sobre las coplas procedentes de la Genizah de El Cairo (Gutwirth 1996, p.396), asegura que gracias al colofón del códice «Neophiti» de la Biblioteca Vaticana, podemos deducir que es indudable la existencia de una versión impresa de las mismas anterior a 1533.

Subrayemos para nuestras reflexiones finales el hecho de estar compuesto en cuaderna vía, además de presentar una riqueza literaria fruto de la conjunción de elementos literarios, populares y de origen rabínico, lo que convierten al poema en único.

\subsection{TRANSMISIÓN Y EDICIONES}

La tradición de esta obra, tanto en manuscritos como en ediciones, es bastante exigua, puesto que los testimonios que conservamos son solamente copias muy posteriores a la fecha de composición y han llegado a nosotros en forma de manuscritos en escritura aljamiada hebraica (como sucede con uno de los códices que contienen la obra de Sem Tob), lo cual indica que fueron preparadas para el uso de judíos, y no de judíos y cristianos. Hasta mediados del siglo pasado, solamente se conocían dos testimonios de esta obra. Las investigaciones sobre la misma provocaron el interés de los eruditos, hallándose un tercer texto, así como un conjunto de fragmentos más breves ${ }^{36}$. Los manuscritos son: a) Biblioteca Nacional de París, hoy perdido, data del siglo XV, y fue

\footnotetext{
35 En este punto notamos una gran discrepancia entre dos de los principales editores del texto: González Llubera (1935), que resalta más otros aspectos que el valor literario del texto en sí, frente a Girón y Minervini (2006), que ensalzan la forma de composición del mismo, así como su contenido y estructura. Esta diferencia probablemente se deba al período cronológico que separa ambas ediciones, puesto que la edición de Girón y Minervini cuenta con muchos más testimonios y recursos que la de González Llubera, y su estudio de las fuentes es, asimismo, más profundo, lo que permite a sus editores estudiar con mayor profundidad la cuestión de las fuentes de las que el poema deriva, así como el ensamblamiento y articulación de las mismas en el conjunto.

${ }^{36}$ Para una descripción más detallada de los manuscritos véase Girón y Minervini (2006).
} 
publicado por Moïse Schwab (1910) y Manuel Alvar (1960, pp.755-757); b) Cambridge University Library, Add. 3355, que contiene una copia defectuosa del texto que fue editada por González Llubera (1935); y c) Biblioteca Vaticana, Neofiti 48, descubierto en 1960 y editado por Moshé Lazar en 1990 (Lazar 1990) junto a otros dos testimonios aljamiados temáticamente emparentados con la figura bíblica de José37.

A los tres grandes testimonios mencionados se añaden cinco más de carácter fragmentario, detalladamente descritos por Girón y Minervini (2006).

\section{LA COMPARACIÓN DE LAS COPLAS DE JOSEPH CON EL POEMA LATINO VERSUS DE JACOB ET JOSEPH}

Aunque el texto bíblico que venimos citando sirve como punto de partida para los dos poemas que vamos a analizar, estos presentan un tratamiento muy diferente del tema. Al ocuparse de José fuera del contexto bíblico y de la historia de Israel, ambos autores se ven obligados a organizar la materia de una manera diversa a como se encuentra en el libro del Génesis; y a dedicar una amplitud mucho mayor a episodios como el encuentro de José con sus hermanos en Egipto, que al resto de las historias que acompañan originalmente a la imagen de su personaje. Por la misma razón, en ambos textos pierden relieve los últimos años de la historia de José y mucho más de Jacob, del que apenas tratan. De este modo, cada uno va a insertar en la historia sus propias cosmovisiones y preocupaciones que aquí intentaremos identificar, que serán, a su vez, un reflejo de los ideales propios de cada una de las culturas, a través de la figura de José como arquetipo.

Para poder llevar a cabo nuestro análisis, estudiaremos individualmente y de forma comparativa algunos de los aspectos que nos parecen más significativos en el desarrollo de ambas obras en lo que al tratamiento del tema respecta ${ }^{38}$. En este sentido, no pretendemos ser sistemáticos en nuestra comparación, sino resaltar aquellos aspectos a los que cada uno de los textos ofrece un tratamiento particular. No pretendemos, pues, hacer una comparación entre ambos, sino observar cómo dos poemas con un punto de partida común ofrecen un resultado muy diferente en función de los elementos que desarrollan y combinan en sus narraciones ${ }^{39}$. Estas diferentes vías de desarrollo nos plantean, sin embargo, interesantes problemas que entroncan directamente con la esencia de los constituyentes de la métrica medieval.

\footnotetext{
${ }^{37}$ Uno de ellas son las Coplas de Yosef ha-Saddiq, compuestas antes de 1732 por Abraham de Toledo y popularizadas a través del imperio otomano, versión que ha sobrevivido oralmente y ha llegado hasta nosotros junto a dos nuevas versiones. Dicho texto es de gran importancia para nuestro trabajo porque presenta una versión de la historia de José que se encuadra dentro del ámbito de la literatura sefardí. La tercera parte de la edición de Lazar contiene una versión en prosa del Sefer ha-Yašar, reelaboración midráshica del Pentateuco que incluye la historia de José, y escrita originariamente en hebreo con la traducción correspondiente.

${ }^{38}$ Obviaremos, por tanto, cuestiones relativas a otros aspectos como el estudio de las fuentes, las formas métricas o los procedimientos retóricos concretos utilizados por cada uno.

${ }^{39}$ Por esta razón, tampoco hemos pretendido analizar todos los motivos que aparecen ni segmentar los poemas de forma sistemática.
} 


\subsection{CARACTERIZACIÓN DEL MARCO Y LOS PERSONAJES}

\subsubsection{El MARCo: LAS EdAdES DEL Mundo}

Las diferencias en el tratamiento de ambos textos comienzan a apreciarse desde el planteamiento del marco en que las historias se desarrollan. El motivo de las edades del mundo se encuentra en el poema latino y no en el judeoespañol, que obviando marco alguno, empieza centrándose en la descripción del personaje de José. En el poema de Paulino la cristiandad, que ha tomado perspectiva frente a los judíos con el tema de las Edades del mundo ya claramente formulado en San Agustín, muestra su optimismo ya que el mundo, en la época de José, está en la tercera edad, y goza de floreciente juventud. Comienza esta tercera edad con el nacimiento de Abraham, quien a través de sus descendientes va a abrir el camino a José (estrofas 1-4).

\begin{tabular}{|c|c|}
\hline Tertio in flore mundus & adhuc dum pubescer \\
\hline In decore iuventutis & seculum pulchrescer \\
\hline Atque proles subter omnes & latos caeli cardines \\
\hline Germinando pullularet & humana feliciter, \\
\hline $\begin{array}{l}\text { Natus est homo in mundum, } \\
\text { Abraham dei amicus, } \\
\text { Heber aurea de stirpe } \\
\text { A quo coepit Hebreorum }\end{array}$ & $\begin{array}{l}\text { patriarcha nobilis, } \\
\text { puer fidelissimus; } \\
\text { oriundus extitit, } \\
\text { diffamari populus }{ }^{41} \text {. }\end{array}$ \\
\hline
\end{tabular}

\subsubsection{LA FIGURA DE JOSÉ, EL HÉROE}

La figura de José aparece en ambos textos como personaje principal y protagonista, caracterizado como un arquetipo y modelo a imitar. En ambas narraciones se nos transmite la caracterización heredada del Génesis ${ }^{40}$, en la que se nos habla de la belleza de José. Así, el poema latino, en la estrofa 6 habla de su personaje como:

Erat pulcher in aspectu, venustus in specie,

Lilii ad instar nitens, $\quad$ roseus ut rosula (estrofa 6, 3-4)

E igualmente el texto judío recoge esta imagen afirmando: «Muy apuesto andaba como rosas y flores ${ }^{42}$. Sin embargo, este último añade que José era un hombre de estatura gigante, lo que ensalza su imagen como gran héroe liberador. Esta popular perspectiva de magnitud se encuentra ausente en el poema latino. Desde el punto de vista de la Teología cristiana la belleza se relaciona íntimamente con la gracia, incluso al releer el Antiguo Testamento.

\footnotetext{
40 Gen. 39,6.

${ }^{41}$ Para las referencias al texto latino, citamos el que aparece en el fascículo 2 del volumen IV de la edición de los Poetae Latin Aevi Carolini en los Monumenta Germaniae Historica, pp.462-471.

42 26.a Para las referencias, remitimos a la edición de Girón y Minervini (2006).
} 


\subsubsection{LA PIEDAD DE JOSÉ}

La piedad de José es otro de los elementos que caracterizan al personaje protagonista de la historia. El texto latino señala que a Jacob, Deus dilexit in specie (estrofa $4,2)$ quien, a su vez amaba de modo especial a José: quem dilexit super omnes natos singulariter (estrofa 5). Es importante resaltar este lenguaje del poema porque se va a mantener constante a lo largo de toda la redacción del mismo: es un lenguaje arraigado en una larga tradición patrística y teológica. El amor de Dios es el principio de la creación, de la redención y de la moral.

El texto hebreo presenta a José y a su piedad de una forma mucho más humana, pues dice que «siempre temiera al Dio de los fonsados» (2a), tema que no pone de relieve el poema latino cristiano. El temor de Dios en el poema judío es todavía veterotestamentario, tal y como es la propia figura de José. Además, añade que cometió pecados que se encuentran en la raíz de lo que sucederá, pues era pastor de ganados, al igual que sus hermanos y «allí luego fiziera uno de los pecados / cuando los ribolbiera con su padre Yosef» $\left(2 \mathrm{~cd}^{43}\right)$.

\subsubsection{LA RELACIÓN ENTRE JACOB Y JOSÉ}

El texto latino, siguiendo mucho más fielmente el Génesis, recuerda que Jacob engendró a José en su vejez y que lo amaba más que a los otros hijos. El texto judeoespañol se ocupa de tal tema, pero en conexión con la túnica: «Su padre lo quería, querençia muy granada / y luego le fazía una aljuba onrada» (3ab), que es la causa de la revolución de la relación de los hermanos con el padre y con José.

\subsubsection{LA TÚNICA}

El poema latino le dedica una amplitud considerable a esta prenda de vestir, con algunos ecos de la Vulgata: fecit illi pater suus tunicam talariam, vario polimitoque contextam de stamine (estrofa 6,1-2). En el texto judío, en cambio, aparece sólo la palabra: «aljuba onrada».

\subsubsection{LA RELACIÓN DE JOSÉ CON SUS HERMANOS}

En este punto, las perspectivas de ambos poemas coinciden, aunque, según el texto latino, la envidia entre los hermanos surge cuando José revela sus sueños, mientras que en el hebreo había surgido ya antes: «Ermanos que avía, non le tenían en nada, / mas gran envidia avían como andaba Yosef» (3cd).

\subsubsection{LOS SUEÑOS}

El poema carolingio teoriza sobre el sueño de un modo diferente al judío, que lo hará posteriormente en el diálogo con la madre ${ }^{44}$. Ejemplo de esta reflexión es la estrofa 7:

\footnotetext{
${ }^{43}$ Episodio que remite a su fuente en Gén. 37.2.

44 También en la Biblia se subraya la envidia de los hermanos previa a los sucesos, Gen. 37, 3-4.
} 
Hic in nocte soporatus

Vidit somnia, quae patri

Quae invidiae tulerunt

Odiique cum livore presagum per spiritum

fratribusque retulit

dictis seminarium

ministrabant fomitem (estrofa 7)

El sueño cristiano procede del Espíritu; es un sueño profético, manifestación de lo divino, todo dentro de una visión de la historia completamente providencialista y predefinida en la mente de Dios y en el acontecer.

\subsubsection{El ÁNGEL GABRIEL}

Aquí encontramos una de las mayores diferencias entre ambas obras. En el texto bíblico $^{45}$ se nos habla de que José, buscando a sus hermanos halló un hombre que le preguntó: «¿Qué buscas?».

El poema carolingio omite esta escena; pero el texto hebreo tiene detrás una gran tradición oral de tipo midráshica que había visto en el hombre un ángel y aquí nuestras coplas dependen de tal tradición, más popular. Son dos estrofas de cuaderna vía lo que en el poema ocupa este detalle (vv. 25-36), que, además, pasa de ser una anécdota sin relevancia a convertirse en un anuncio del ángel a José sobre las amenazas venideras, lo que provoca que José se encuentre predispuesto y precavido ante dicha situación.

Enco[n]tró en la carrera al ángel Gabri'el

e luego él se foera a preguntar a él

si á visto pasar a fijos de Yisra'el,

e luego respondiera el ángel a Yosef. (estrofa 8)

\subsubsection{El ENCUENTRO DE JOSÉ Y SUS HERMANOS}

El poema latino presenta a los hermanos del protagonista como seres falaces y malvados. Solamente José es figura del Mesías, mientras que los demás son pecadores.
Cumque eum fratres sui
Recordati somniorum
a longe prospicerent,
pleno dolo pectore:
«Ecce», inquiunt, «advenit
Hunc, venite, occidamus
somniator presagus;
et celemus sanguinem». (estrofa 11)

El judeoespañol, en cambio, justifica su actitud, recalcando que veían a José como «malo» (v. 40), aunque justifica su malevolencia con notas sugerentes (13ab).

Del mal que fazían non se demoraban,

sentábanse e comían y sos ojos alçaban:

gran recua veían de moros que pasaban.

Entonces fazía bien Yehudah a Yosef.

\footnotetext{
${ }^{45}$ Gen. 37,15 .
} 


\subsection{LA TRAMA DE LA HISTORIA}

\subsubsection{EL EPISODIO DEL POZO}

Dominado por un lenguaje escueto, el texto carolingio se limita a enunciar que José es arrojado a un pozo: Et in lacum recluserunt innocentem puerum (estrofa 12, 4), mientras que las coplas enfatizan lo dramático de este acto mediante la adición de elementos repugnantes que sirven para dar un desarrollo literario mucho más amplio a lo que en el otro poema aparece casi como anecdótico: «En pozo lo echaron de sierpes [y] guzanos / En él lo dexaron solo a Yosef» (12cd). La fuente bíblica señala, en cambio, que el pozo no tenía agua, por lo que estos añadidos del poema judío se deben a otras influencias que de nuevo remiten a una tradición propia, probablemente de raigambre popular, que no aparece alegorizada en el midrásh.

\subsubsection{LA PRESENTACIÓN DE LOS HERMANOS}

Mientras que el texto latino omite la presentación de los hermanos, las coplas lo hacen con detalle. Vale la pena destacar especialmente la actuación de Rubén y de Judá. A Judá además lo presenta como «el fuerte, como osos e toros» (verso 53), del mismo modo que presentó a José como un «gigante». Esta presentación va a tener una continuación posteriormente en la actuación de los hermanos frente a José, cuando aún no lo conocen ${ }^{46}$. En las coplas, José, mientras va a Egipto pasa temores de muerte. Además, es espléndida la descripción de juramento de los nueve (porque faltaba Rubén). Parece que conjuran a la sekinah como testigo de su juramento ${ }^{47}$. Todos estos elementos se encuentran ausentes en el texto latino, que, como venimos señalando, es mucho más escueto y conciso en sus descripciones y caracterizaciones. En el texto judío subyace la apología a los 12 patriarcas, representados en los hermanos de José, que es esencial para el pensamiento judío.

\subsubsection{LA REACCIÓN DE JACOB ANTE LA NOTICIA DE LA MUERTE DE JOSÉ}

En el texto latino es muy notable. Abarca cinco estrofas (14-18), y produce la impresión de ser casi una escena teatral $($ Gen. 37, 33) o incluso una representación teológica en la que la víctima, José, es figura de Cristo, por quien realmente se lamenta Jacob «teológicamente» ${ }^{48}$. De hecho, el autor utiliza para este episodio un lenguaje muy cuidado y elegante. Estas cinco estrofas (14-18) son una de las partes más llamativas del poema carolingio; fragmento que, además, ha sido objeto de un importante desarrollo en el teatro josefino del Siglo de Oro español, como se ve en las versiones de Miguel de Carvajal, Lope de Vega y Matatías de Aboab ${ }^{49}$.

\footnotetext{
${ }^{46}$ Hemos de advertir que la fuerza descomunal de los hermanos es un motivo midráshico que además coincide con percepciones folclóricas sobre los héroes épicos.

${ }^{47} C f$. Girón y Minervini (2006, nota 16a-d).

${ }^{48}$ Cabe notar con todo, que la alegorización de José como figura Christi es más bien implícita en cuanto al realce de la imaginería «sacrificial».

${ }^{49}$ Recogido en Girón y Minervini (2006, p.228, notas a los versos 21a-d).
} 


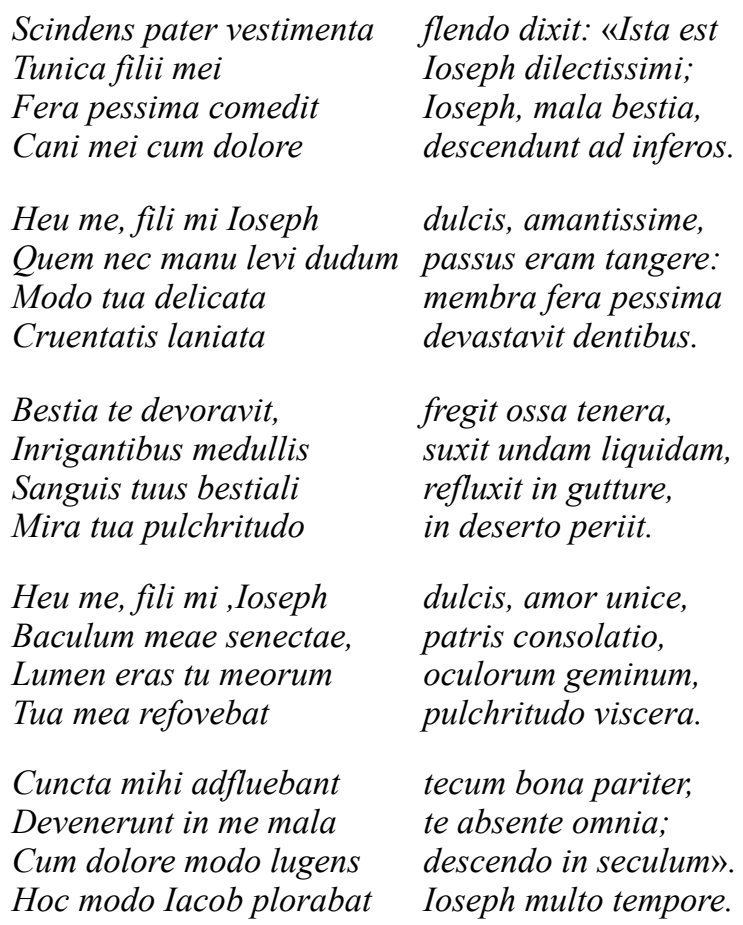

Las coplas en cambio, solo dedican una estrofa a este episodio (vv. 81-84), que pasa mucho más desapercibido dentro del conjunto. Jacob es el padre de los patriarcas y el poema refleja la mentalidad colectiva del pueblo. No le interesan las divisiones ni rupturas.

Ya'aqob coando la vido en aquellas çazones

fizo grande apellido e dixo estas razones:

«Fijo eres comido de osos u de leones,

mas nonca abré en olvido a mi fijo Yosef.»

\subsubsection{El VIAJE A EGIPTO}

El texto latino lo omite, mientras que las coplas lo pormenorizan. Es especialmente imponente la escena del diálogo con el espíritu de su madre (vv. 86-91), cuyo dramatismo resulta muy propio del poema en cuaderna, ya que indica la posible recitación del mismo ${ }^{50}$.

\footnotetext{
${ }^{50}$ Sobre el tema de la manifestación oral o escrita de los poemas en cuaderna vía, así como de los rasgos definidores de la poética del denominado «mester de clerecía» he tratado en mi artículo «El exordio de los poemas romances en cuaderna vía. Nuevas claves para contextualizar la segunda estrofa del Alexandre») (González-Blanco 2009). En el poema judío, las referencias a una realización oral del texto son constantes, pues su autor trata constantemente de acercar el contenido del mismo a sus oyentes mediante la adición de elementos de su entorno que estos puedan identificar como parte de su cultura popular.
} 
Yosef ya lo levaban por carreras de Efratah, do estaba soterrada la so madre unrada, e ansí le dezía y ansí le hablaba: «iAy madre, al Dio ruegues por tu fijo Yosef!»

Dixo: «Fijo non temas ni tomes coidado, que allá donde te llevan tú serás bien onrado: los sueños se afirmarán que tú as soñado.» Loego se le volvían sos colores a Yosef. (estrofas 22-23)

\subsubsection{LAS TENTACIONES EN CASA DE PUTIFAR}

Este episodio ha sido uno de los más fructíferos en muchas tradiciones orientales de la historia de José. Sin embargo, el poema carolingio lo reduce a una fórmula más bien críptica (estrofas 19-20):
His peractis venundatus
Innocens in lacum missus,
est Joseph in Aegypto;
Non adsensit perpetrare propter quod nefarium
Factus est princeps in terra opus, deum diligens;
Aegypti gratissimus.
In illo timuit peccare
qui clementer eum sua
cuius erat famulus, circumcinxit gratia.

Las coplas, en cambio, participan de esta tradición legendaria y les dan una amplitud considerable (vv. 101-152). Entreteniéndose en detalles escabrosos, se describen elementos tomados de la vida real, de las creencias y concepciones judías y en general populares ${ }^{51}$.
Respondió so señora
«Tu fas me enamora
como desvergonçada:
¡Yaze conmigo agora, non sea mistura
Luego respondía otra razón Yosef.
e soy tu desdeñada.

«Aunque fuese cierto de non aver mestura, sabe lo encobierto el Señor del altura, vee el que faze tuerto, dale mala majadura.

$\mathrm{Gra}[\mathrm{n}] \mathrm{de}$ sería el riebto que echarían a Yosef.» (estrofas 29-30)

\subsubsection{EN LA PRISIÓN}

En el poema latino, la composición de la estancia en la cárcel de José es sofisticada, pero estructuralmente construida y centrada solamente en lo esencial. No se cuenta lo

\footnotetext{
${ }^{51}$ Cabría precisar el tono moralizante de la tradición exegética judía aquí recogida en contraste, por ejemplo, con el tratamiento más ambiguo de las versiones islámicas.
} 
sucedido en casa de Putifar, ni se comienza narrando lo que ha acontecido en la cárcel, pero prolépticamente se dice que José va a predecir al Faraón los siete años de abundancia y los siete de carestía. Tras tal anuncio, comienza a explicar cómo llega esa predicción, pero sólo cuenta los sueños felices del copero del Faraón y no todo lo superfluo al respecto, que queda omitido. Después narra el sueño del Faraón y su interpretación.
In illo timuit peccare,
cuius erat famulus,
Qui clementer eum sua
circumcinxit gratia.
Pharaoni indicavit
septem laeta tempora,
Septem tristia predixit
post haec redeuntia.
Nam cum inter multos esset dampnatos in carcere,
Pharaonis vinifusor
Ioseph refert somnium:
«Tres propagines florentes,
Vidi pendere in vite,
tres uvas sub pampino
pulchris cinctas gemmulis». (estrofas 20-21)

Por el contrario, las coplas realizan una amplificación considerable de este episodio, añadiendo complejidad en la narración y los personajes que en ella participan, tratando de acercar la narración a sus lectores u oyentes.

\subsubsection{LA NARRACIÓN DE CÓMO SALIÓ JOSÉ DE LA CÁRCEL}

El texto latino es escueto, selectivo. Sólo describe los datos esenciales, nada dice del panadero del Faraón y sólo habla del copero, relata su sueño y le pide que interceda y después cuenta el sueño del Faraón que hace que el copero se acuerde de José. En este caso, una vez más, las coplas se detienen en todos los detalles alargando considerablemente el episodio: los sueños del copero y del panadero con significados contrarios; los sueños del Faraón y la noticia que le da el copero; el mandato de soltarle. Después especifica los sueños: las siete vacas, las siete espigas. La prueba a que someten a José, y los episodios que siguen, con gran pasión en la narración.

\subsubsection{El ENCUMBRAMIENTO DE JosÉ}

El poema latino, como acostumbra, narra este pasaje escuetamente, pero con mucha precisión (estrofa 25, 3-4 y 26,1); las coplas también son escuetas, pero de manera diferente: mientras el texto latino se refiere al encumbramiento del personaje cuando éste alcanza anillo y púrpura y un torque áureo en el cuello y cetro en la diestra, haciéndole Dios del cielo «Señor supremo del mundo»; las coplas no se detienen en nada de esto: «Sobre mi reinado quiero que seas guía / señor serás nombrado, Yosef, por tu valía» $(67 \mathrm{bc})$. El texto latino presenta en este pasaje, al igual que en muchos otros, un tono cortesano, clerical y más culto, mientras que las coplas se mueven en un ambiente más cercano al mundo popular:

Quam ob causan est adeptus [tor]quem auream in collo anulum et purpuram et sceptrum in dextera (estrofa 25, 3) 
Fecit eum deus caeli Multa nimirum frumenta Quibus postea prudenter Et famosam adquisivit summum terrae dominum.

recondit in horreis,

mundi famen reppulit

gloriam per secula. (estrofa 26)

Son especialmente llamativos los signos de autoridad (anillo y púrpura, torque de oro en el cuello y cetro en la diestra). El Dios del cielo le hace señor de la tierra, mundo muy diferente del de las coplas:

\author{
«Lleno de bondades y de sabiduría \\ para mis Çibdades sera muy buena guía \\ si me lo consejades dezírselo quería \\ marabíllome si falla[d]es tal guiador commo Yosef» (estrofa 64) \\ «Pues que é probado la tu sabiduría \\ sobre mi reinado quiero que seas guía: \\ Señor serás nombrado, Yosef, por tu valía \\ y sea anparado mi pueblo por Yosef» (estrofa 67).
}

\title{
4.2.9. El HAMBRE
}

El tratamiento de este motivo es similar al que hemos visto en otros casos. El poema latino habla escuetamente, las coplas escenifican. El poema carolingio reduce el texto bíblico ${ }^{52}$ a dos líneas:

\section{Omnis Aegyptus et cuncta Chanaan confinia \\ Famis coepit consummari valide penuria (estrofa 27, 2-3).}

Las coplas, por el contrario, se deleitan describiendo y siguiendo mucho más de cerca el texto original. Comienzan ya haciendo una escenificación del hambre que había de venir:

La fanbre era tan fuerte en toda la tierra

bozes daba la gente al rey de esta manera:

«iEscápanos de muerte, señor, dános çivera!»

Tomó muy mal talente, dixo: «iIdvos a Yosef!» (estrofa 73)

A su vez, advierte el carácter providencial del hambre:

$\mathrm{Y}$ el que guardó çivera non le quedava grano ${ }^{53}$. que luego naçiera en ello el gusano.

mas el Dio allí pusiera su graçia y mano.

por que bien se vendiera çibera de Yosef. (estrofa 71)

${ }^{52}$ Gen. 41, 54-57.

53 Nuevamente aquí nos encontramos con un detalle midráshico. 
Finalmente describe el hambre con más pormenores:

\author{
Los años de fartura todos eran pasados \\ Años de la rincura ya eran començados \\ La gente con questura andavan desarrados \\ Segun la soltura que soltara Yosef. (estrofa 72)
}

\title{
4.2.10. El ENCUENTRO DE JOSÉ Y SUS HERMANOS
}

Artísticamente, está perfectamente construido en las coplas, mucho más detallado que en el poema latino, en el que meramente se indica que se produce el encuentro (estrofa 28) siguiendo el episodio del Génesis. Resulta admirable que lo esencial sea todo el conjunto de estratagemas para humillar y hacer aprender a sus hermanos hasta llegar a la manifestación de sí mismo como clímax del poema.

$\begin{array}{ll}\text { Inter alios et Ioseph } & \text { fratres cum pecunia } \\ \text { Advenerunt, ut mercari } & \text { potuissent triticum: } \\ \text { Qui videntes Ioseph proni } & \text { super terre faciem } \\ \text { Supplici adoraverunt } & \text { cum timore pectore. (estrofa 28) }\end{array}$

En las coplas, en primer lugar, José se acuerda de su padre (74d) y hace que, previendo que habían de venir a comprarle a él trigo, estableciera porteros en Egipto (75). Providencialmente, José echa paja en los ríos (74c), que va a ser la que vea Jacob (76). Este detalle de la paja debe haber sido elaborado en la tradición midráshica para explicar cómo se les ocurrió a los israelitas bajar a Egipto, pero de esto no hay nada en el texto del Génesis ni en el poema latino. Las coplas amplían muchísimo el discurso de Jacob, componiendo hasta 600 versos frente a las 30 estrofas del poema carolingio (27, v. 4 hasta la 57), es decir, 120 versos.

Se puede decir que, mientras el poema latino recoge lo esencial del texto bíblico, en el que se recalca, en la estrofa 54:
An $n<$ esci $>$ tis, quia mei
non est alter similis
in auguriis seu rebus archanis et mysticis?
liberi vos nunc abite,
deum ego timeo,

Las coplas amplían hasta tal punto este pasaje que componen otro subpoema deleitándose en la historia de Israel en general y de los hijos de Jacob en particular (estrofas 74-225, lo que es casi mitad de las coplas).

\subsubsection{LA HUMANIDAD DE LOS HERMANOS DE JOSÉ}

Se trata de un motivo que, frente a su ausencia en el texto latino, aparece muy desarrollado en el poema castellano. José se encuentra a sus hermanos en la calle de los burdeles (estrofa 82bc):

En una calle eran mugeres de maldad:

en ésta los fallaran a todos en poridad. 
Esto no lo recoge el texto bíblico, pero sí algunos midrashim, que explican que fueron allí en busca de su hermano por si eventualmente y dado que era de buena presencia, podría haber sido vendido para prostitución masculina ${ }^{54}$. El problema es que el texto bíblico no dice nada de que los hermanos de José hubieran sido encontrados en el zoco y en la calle de las prostitutas. Y que en el fondo era una tradición oral que seguía siendo ejercitada por los rabinos al comentar la tradición judía, de un modo similar a como ocurre ahora con la predicación cristiana que cada orador da su propia explicación de los textos. En nuestro caso el detalle habla o bien del afán de los hijos de Jacob en ocultarse de la oficialidad, o bien de su humanidad al tratar de desahogarse con las prostitutas. También podría tratarse de un recurso de la redacción, ya que en las estrofas siguientes se les acusa de no haber entrado por la puerta y que a qué viene el «buscar la comida» donde están las malas mujeres (estrofa 89b), a lo que los hermanos parecen indicar que estaban allí buscando a José (estrofa 90ad y estrofas 212, 213 y 214).

\title{
4.2.12. LA FORTALEZA DE LOS HERMANOS DE JOSÉ
}

Otra de las caracterizaciones sobre las que insiste el poema aljamiado es en la fortaleza de los hermanos. El autor aprovecha la ocasión para hacer un excurso sobre la fortaleza de los judíos hermanos de José (estrofa 104 y siguientes). Volverá a destacar esta virtud de sus hermanos en las estrofas 156, 159 y 160 . También en el canto a Judá, además de los cantos a Simeón y Rubén de los que hablaremos a continuación.

\author{
Maguera eran fuertes y todos de buen sezo, \\ mucho eran temientes porque les era seso \\ y non eran savientes a cuál echaría prezo. \\ A Šim'o[n] tuvo mientes esa ora Yosef. (estrofa 104)
}

\subsubsection{LOS DOS HÉROES: RUBÉN Y SIMEÓN}

Aquí viene el poema de Simeon «El Fuerte» (estrofas 104-110). Sólo le puede vencer el fuerte Menaseh (estrofa 110). Simeón queda preso en Egipto como se repite insistentemente (estrofas 121, 123, 125 y 137) El tema de la fortaleza se reiterará en el poema de Judá «el poderoso» (estrofas 179-210).

\subsubsection{El ENCUENTRO CON BENJAMín}

También ausente en el poema latino, ocupa varias estrofas en el castellano y sirve para preparar las estrofas siguientes que narran la historia del vaso (160-175). El encuentro mismo es estructurante bíblico (Gén. 43, 29ss.), mientras que el diálogo entre José y Benjamín es una elaboración midráshica de fuentes conocidas ${ }^{55}$.

\footnotetext{
${ }^{54}$ Edición de Girón y Minervini (2006, p.263).

${ }^{55}$ Estas fuentes se hallan descritas con detalle en las notas a las estrofas 142-144 de la edición de Girón y Minervini (2006, pp.272-273).
} 


\subsubsection{LA MANIFESTACIÓN DE JOSÉ}

Aquí regresamos al texto canónico, en el que ambos poemas vuelven a confluir, aunque de una forma un tanto teatral, salpicada con reflexiones y recreaciones sobre los planes de los que desean matar a José, la intervención del ángel para sosegarlos y corregir sus intenciones, y el miedo sufrido por el propio José. El texto latino es relativamente largo al tratar este aspecto:
«Ego sum en», inquit, «Joseph, frater vester iunior
Ego sum quem vindedistis
iam dudum in Aegyptum;
Vivit adhuc meus pater,
Super singulos amare
adhuc vivit senior?»
Beniamin super collum
flevit, dedit oscula,
flevit amarissime.
«Vos flexistis hoc in malum,
deus iustus, paciens
vertit illud nunc in bonum.
Nolite pavescere!
Pro salute vestra deus
misit me in Aegyptum,
Dei hoc, non vestro fuit
peractum consilio. (estrofas 57-59)

\subsubsection{El MENSAJE AL PADRE JACOB}

Se trata de un pasaje cuya interpretación es compleja ${ }^{56}$. El poema de Paulino de Aquilea es, en cambio, teológico y no tiene falta de prueba alguna. Las palabras de José son palabra de Dios:

Ite, meam nuntiate

Adhuc restant quinque anni

Ad me <veniat $>$ festinus,

Sua simul eum pascam meo patri gloriam!

famis <in> inopia;

ego $<$ fratres nu> triam,

cuncta cum progenie». (estrofa 60)

Y así lo hacen los hermanos una vez llegados a Canaán:

«Ioseph vivit, ipse regnat

Ipse dominus est terre, super < cunctam > Aegyptum,

ipse regit populum». (estrofas 61, 3-4)

Las coplas, en cambio:

Y dezid: «Aquél que me deseava, mi padre el gran letrado, que cuando [a] vós me inviava espartióme de su lado, estonses con él meldava en un libro muy preçiado.» Estas señas dava a sus ermanos Yosef. (estrofa 229)

\footnotetext{
${ }^{56}$ Lo han hecho de buena mano Girón y Minervini (2006, p.38).
} 
Aquí es donde mejor se percibe la diferencia de público al que ambos poemas van dirigidos, así como cuán diversos son. Para ambos mundos es importante el personaje protagonista, pero para el mundo culto latino, la importancia está dentro de la historia de la salvación, puesto que sigue con mucha mayor atención la fuente bíblica; mientras que para el judío la parte central está en la historia del pueblo judío cuya salvación está lo mismo que la de los hijos de Jacob en las manos de Dios.

\subsection{EL DESENLACE DE LA HISTORIA}

Recapitulando, observamos que en el poema latino este pasaje ocupa 30 estrofas de 69, es decir, algo menos de la mitad; mientras que en las coplas ocupa casi exactamente la mitad, en tanto que el texto bíblico del Génesis dedica a esta parte tres capítulos 42, 43 y 44, es decir, menos de un tercio del conjunto. La Biblia, en cambio, concede el capítulo 45 a la glorificación de José, episodio al que los dos poemas apenas le dedican unas líneas a modo de esbozo. Esta diferencia y coincidencia nos pone ante la verdadera esencia de los poemas medievales. En ellos ya no interesa la muerte de Jacob, ni la historia final de Jacob, sino sólo referencialmente. En el poema carolingio todo es mera narración escuetísima o síntesis teológica: De la historia o biografía narrada, solo interesa el hecho de que José es figura de Cristo en su pasión. Podemos distinguir:
a) invitación (estrofa 60)
b) vuelta a Canaán (estrofa 61, 1-2)
c) mensaje a Jacob (estrofa 61,3-4)
d) respuesta de Jacob ya viejo y casi moribundo (estrofa 62)
e) viaje de Jacob a Egipto (estrofa 63)
f) abrazo con José (estrofa 64)
b) muerte de Jacob (estrofa 65)
c) aumento de los israelitas en Egipto (estrofa 66, 1-2)
d) muerte de José (estrofa 66, 3-4)
e) oráculo de José antes de morir (estrofa 67$)^{57}$
f) valor de la historia de José como figura de Cristo (estr. 68)
g) doxología (estrofa 69)

En las coplas, la distribución es la siguiente:

a) Bajada de Jacob a Egipto

- la invitación (estrofas 236-240)

\footnotetext{
${ }^{57}$ Esta forma de organización resulta altamente interesante, porque recuerda la mentalidad judía, pero también la griega y parece encontrarse alejada de la cristiana, o quizás solamente asemejarse a esta en el culto a las reliquias.

scio, quia visitabit vos deus altissimus, absportate hinc vobiscum mea ossa, obsecro, quod non mihi, sed proderit vobis in perpetuum (estrofa latina 67, 2-4)
} 
- la embajada a Canaán (estrofas 241-252), que corresponde a Gén. 45, 28. «vadam», inquit, "et videbo dulcem deum filium / antequam ad ima ruam seu priusquam moriar» (correspondiente a la estrofa latina 62, v. 3-4).

- el camino y asentamiento (estrofas 253-267) El encuentro con Jacob es muy diferente en el texto latino. Es un lenguaje elevado que recuerda al final del libro de Job, pero que es nuevamente una perífrasis fiel a Gén. 46, 30.

Dixit: «Letus moriar, / Quia merui videre, fili, tuam faciem» (estrofa latina 64, versos 2-3)

b) Muerte de Jacob (estrofas 276-282)

c) Entierro de Jacob (estrofas 283-286)

d) Conflicto con Esaú (estrofas 287- 294)

e) Vida en Egipto después de muerto y enterrado Jacob (estrofas 294- 303)

f) Muerte y entierro de José (estrofas 304-306)

g) Reflexiones finales sobre historia venidera y temas editoriales (estrofas 307-310)

\section{REFLEXIONES FINALES}

Tras la comparación realizada entre ambos poemas, podemos concluir que, a pesar de narrar la misma historia, la forma, contenido y detalles de los textos resultan muy diferentes, y no parece probable que exista una relación de dependencia entre ambos. En los dos poemas encontramos tradiciones diversas, intereses distantes, y elucubraciones de la misma historia desde distinto sistema de valores. El texto latino ofrece la interpretación cristiana del Antiguo Testamento. El texto hispanojudío realiza la reflexión de la comunidad judía de su propia historia y problemática. Todo ello es, en principio, normal y previsible, tratándose de poemas separados por cuatro siglos de evolución histórica y religiosa diferente. No obstante, resulta altamente interesante poner ambos en relación, para así, observar el diferente tratamiento que cada uno de ellos hacen del mismo tema.

\subsection{SEMEJANZAS ENTRE AMBOS POEMAS}

A pesar de las divergencias, a grandes rasgos ambos poemas coinciden en el armazón de la historia siguiendo las directrices bíblicas: José hijo de Jacob, junto a otros once hermanos, era amado por su padre, que le regala una túnica multicolor. Sueña y sus sueños ofenden a los otros. Un día, el padre le envía a informarse de lo que hacen sus hermanos pastores; estos le meten en una cisterna y le venden a unos mercaderes que van a Egipto. José va a la cárcel y allí conoce a otro preso, copero del Faraón por el cual saldrá de la prisión y será honrado por el Faraón por su capacidad de interpretar sueños ${ }^{58}$.

\footnotetext{
${ }^{58}$ Estrofa 23 del verso latino con versos 181-184 de las coplas: cuando salgas habla por mí al Faraón y dile que me han apresado traidoramente y sin razón.
} 
Creemos importante señalar también que los dos poemas coinciden en el interés y selección de la historia bíblica: en ambas piezas la historia posterior es menos importante. Ambos poemas son un canto a José, no una narración de la historia total de José hasta su muerte, aunque en ellos aparezca también la muerte. Por otro lado, parece ser que ambos textos se escenificaron en algún momento, vinculados a determinadas ceremonias de tipo religioso ${ }^{59}$.

También resulta muy marcada y es de especial interés la coincidencia de los dos textos en la métrica, pues el poema latino está escrito en estrofas de cuatro versos de 15 sílabas divididos en dos hemistiquios, y el judeoespañol presenta la misma estructura de versos alejandrinos. Es cierto que el carácter más popular y de tradición oral de las mismas, así como la compleja transmisión a la que el poema se vio sometido ${ }^{60}$, hace que se produzcan ciertas imperfecciones en la rima ausentes en el texto latino, cuyo autor parece ser un poeta de escuela, que cuida en todo momento la exquisita perfección formal, mientras que el autor del poema judío prima el contenido y la inmediatez del mismo sobre la absoluta perfección de la forma, lo que hace, que, al igual que otros muchos poemas en cuaderna vía, no todas las estrofas cuenten con 14 sílabas en todos sus versos ${ }^{61}$.

\subsection{DIFERENCIAS ENTRE AMBOS POEMAS}

El poema latino es un texto culto, religioso, de fuentes bíblicas y finalidad didáctica. Su exquisita pulcritud se observa desde el comienzo, en que enmarca el poema dentro de las edades del mundo, y crea una imagen de José muy tópica, amado por su padre, consuelo de la vejez de éste, y apuesto. El autor insiste en la importancia del sueño, así como en las relaciones entre los hermanos. El texto de Paulino omite lo que no es relevante, como el pasaje del hombre que los otros identifican con un ángel y probablemente lo rechaza como leyenda inventada. Es respetuoso con su fuente, sin añadir muchos elementos externos y procurando ofrecer una imagen escueta y clara de un episodio que es casi ritual. Las coplas, en cambio, ofrecen una visión de los hechos mucho más cercana a su público, cuyo héroe gana en humanidad y cercanía. Además, el texto se elabora mediante una combinación de rasgos de tradición específicamente judía, dando como resultado un poema de gran riqueza que aglutina las fuentes clásicas con un amplio corpus de comentarística rabínica.

${ }^{59}$ La escenificación del poema latino probablemente tuviera lugar vinculada a la liturgia, mientras que en el caso del poema judío el tema josefino se vincula a la festividad litúrgica de Purim.

${ }^{60}$ Entre las que destaca el hecho de estar escrito en aljamía.

${ }^{61}$ En realidad, el único autor castellano que escribe las cuadernas perfectas es Gonzalo de Berceo. El resto de poetas que escriben en cuaderna vía dejan ver en sus textos irregularidades frecuentes en lo que a la norma del isosilabismo respecta. Muchos editores no quieren, en cambio, aceptar esta situación y tratan de regularizar los poemas más allá de lo que su autor lo hizo en su día. Esta es una de las causas que provocan que los investigadores se hayan dividido en dos grupos: los partidarios de considerar propias del mester tan sólo algunos textos del siglo XIII (entre los que se incluyen las obras de Berceo, el Libro de Alexandre y el Libro de Apolonio), y los que aceptan un grupo más amplio de poemas en los que el principio de las «sílabas contadas» y la dialefa no se respetan a la perfección, observándose ciertas irregularidades. Sobre estas irregularidades métricas, véase González-Blanco (2011, e.p.). 


\subsection{INTERÉS DEL TEMA}

$\mathrm{Al}$ analizar estos textos nos encontramos nuevamente ante uno de los grandes problemas de la investigación en literatura medieval española: la delimitación del concepto de «mester de clerecía» y la imprecisión e inexactitud que supone identificarlo exclusivamente con el uso de la cuaderna vía y con ciertas características cronológicas, geográficas o poéticas concretas; pues estos dos textos, inspirados en una misma temática bíblica ¿no ofrecen un tratamiento muy diferente de ella, tamizado por las distintas circunstancias culturales, cronológicas y de composición de cada uno? Así, el poema judío incorpora al marco bíblico tradicional un entramado de sabiduría rabínica y popular cuyos elementos se aprecian a través de los minuciosos y ricos detalles que salpican el texto de las coplas.

Consideramos, pues, que ambos poemas se encuentran dentro del llamado «mester de clerecía», porque entendemos el término en un sentido amplio, es decir, poemas largos de tipo narrativo compuestos por autores cultos con finalidad didáctica, pues por su temática e intención están destinadas al aprovechamiento por parte de sus lectores u oyentes; respetan el texto de sus fuentes, y vigilan el principio de las «sílabas contadas». El poema latino se encuentra, sin embargo, en un estadio muy inicial de este «mester», puesto que cumple a la perfección el principio del cómputo silábico, respetando la norma clásica y siendo escueto en contenidos y descripciones. El poema judío, en cambio, se encuentra en un estadio ya mucho más avanzado del «mester», pues está escrito en lengua romance y se ve sometido, a su vez, a una doble influencia de tradiciones. En este caso sigue estando patente la intención didáctica hacia los lectores, que se manifiesta a través de las múltiples fórmulas y llamadas de atención que aparecen en el texto, además de la alusión constante a elementos propios de su cultura judía extraídos del acervo literario rabínico unidos a materiales tradicionales de la literatura oral y popular de la época. Aunque algunos investigadores se preguntan si podemos seguir considerando este poema como perteneciente al mester de clerecía por el mero hecho de estar compuesto en cuaderna vía y en lengua castellana ${ }^{62}$; sin embargo, ¿considerarían dichos investigadores el poema de Paulino también perteneciente al mester? Probablemente no, puesto que al no estar escrito en castellano sale fuera de la órbita de estos textos. Sin embargo, ¿no es este texto en muchos aspectos muy similar a la «clerecía» de Berceo, que escribe convencido de que lo hace en latín?

Con estas preguntas, quizás todavía sin respuesta queremos extender la noción del concepto de «mester de clerecía» como un fenómeno más amplio, cuyas primeras y más puras manifestaciones tienen su origen en la poesía mediolatina no cuantitativa, y evolucionan a través de las diferentes lenguas romances combinándose con otros elementos, tradiciones y culturas para dar lugar a un fenómeno nuevo que es el de una literatura vernácula con diferentes categorizaciones y realidades que se encuentra en constante evolución. El resultado son obras que distan de los plantea-

${ }^{62}$ Ya hemos hablado más arriba de las diferencias de interpretación del concepto de «mester de clerecía». 
mientos que regían el mester de clerecía propios de la época mediolatina, pues han incorporado y fusionado en su interior nuevas tendencias, esquemas y metros que marcarán la evolución de los nuevos horizontes de la poesía.

\section{REFERENCIAS BIBLIOGRÁFICAS}

Alvar, M. (1960), Textos hispánicos dialectales; antología histórica, Madrid, CSIC.

Alvar, A. (1998), «Tipología de los procedimientos intertextuales en la poesía latina antigua», en Actas del IX Congreso Español de Estudios Clásicos. Literatura Latina, Madrid, Ediciones Clásicas, pp.3-16.

BisCHOFF, B. - EBERSPERGER, B. (1998), Katalog der festländischen Handschriften des Neunten Jahrhunderts (mit Ausnahme der Wisigotischen), Teil I, Wiesbaden, Harrassowitz.

DíAZ y DíAz, M. (1979), «Vigilán y Sarracino: sobre composiciones figurativas en la Rioja del siglo X», en Lateinische Dichtungen des X und XI Jahrhunderts. Festgabe für Walter Bulst, Heildelberg, pp.60-92.

DíAz-MAS, P. (1993), «Un género casi perdido de la poesía castellana medieval: la clerecía rabínica», Boletín de la Real Academia Española 73, 329-346.

Dreves, G. M. - Blume, C. (1886), Analecta Hymnica Medii Aevi, Leipzig, Fues's Verlag R. Reisland.

Du MérIL, E. (1969), Poésies inédites du Moyen Âge: Precedées d'une histoire de la fable esopique, Bolonia, Forni Editore, pp.286-294 [Reimpresión de la edición de 1854].

DüMmLER, E. (1896), «Versus de Jacob et Joseph», Zeitschrift für Deutsches Altertum und Deutsche Litteratur 28=40, 375-384.

Girón-Negrón, L. M., y L. Minervini (2006), Las Coplas de Yosef: entre la Biblia y el Midrash en la poesía judeoespañola, Madrid, Gredos.

GonzÁlez Llubera, I. (1935), Coplas de Yoçef: A Medieval Spanish Poem in Hebrew Characters, Cambridge, Cambridge University Press.

González-Blanco García, E. (2008), "Las raíces del Mester de Clerecía", Revista de Filología Española 88, fasc. $1^{\circ}, 195-207$.

GonZÁlez-Blanco GarcíA, E. (2009a), "La historia bíblica de José en la literatura española, un tema 'eterno"', en VALDIVIESO, J.H. - VALDIVIESO, L.T. (eds.), El español, baluarte del humanismo: literatura, lengua y cultura, Turlock, California, Orbis Press, Serie Reflexión, pp.197-204.

GonZÁlez-Blanco García, E. (2009b), "El exordio de los poemas romances en cuaderna vía. Nuevas claves para contextualizar la segunda estrofa del Alexandre", Revista de Poética Medieval 22, 23-84

GonZÁlez-Blanco GaRCíA, E. (2010), La cuaderna vía española en su marco panrománico, Madrid, Fundación Universitaria Española.

GonZÁlez-Blanco García, E. (en prensa para 2011), "Heterodoxia en la cuaderna vía: Nueva revisión del concepto de las "sílabas contadas" a la luz de los poemas franceses e italianos", eHumanista, [http://www.ehumanista.ucsb.edu].

Guscin, M. (1991), «Versus de Iacob et Ioseph: A reassessment of the Verona codex», Mittellateinisches Jahrbuch 26, 56-69.

Gutwirth, E. (1996), «Coplas de Yoçef from the Genizah», Revue des Études Juives 155, 34, pp.387-400. 
Hagen, H. (1971), Carmina medii aevi maximam partem inedita. Berna, apud G. Frobenium et soc., pp.84-90.

Hassán, I. M. (1983), «Las coplas de Yosef sefardíes de Abraham Toledo y la poesía luctuosa», en Philologica Hispaniensia in honorem Manuel Alvar, vol. 3, Madrid, Gredos, pp.215-220.

LAZAR, M. (1990), Joseph and his brethren: Three ladino versions, Culver City (California), Labyrinthos.

Lote, G. (1973), Les origines du vers Français, Genève, Slatkine Reprints [edición francesa original de 1940].

Madrisius, Giovanni F. (1737), Sancti Patris Nostri Paulini Patriarchae Aquilejensis Ope$r a$, Venecia, Venetiis Pitterius.

MenÉndez y PElAyo, M. (1949), Estudios sobre el teatro de Lope de Vega, Edición Nacional de las Obras Completas, vols. 29-34, Santander, Aldus.

MeYer, W. (1885), «Anfang und Ursprung der lateinischen und griechischen rythmischen Dichtung», Abhandlungen der Münchener Akademie, I Klasse, XVII Band II Abt., pp.268-449.

Millás Vallicrosa, J. M. (1948), La poesía sagrada hebraicoespañola, Madrid, Consejo Superior de Investigaciones Científicas, Instituto Arias Montano.

Minervini, L. (2004), «Les Coplas de Yoçef de la Genizah du Caire», Revue des Études Juives 165, jul.-dic., 429-444.

Norberg, D. L. (1979), L'œuvre poétique de Paulin d'Aquilée, Estocolmo, Almqvist \& Wiksell International.

Norberg, D.L. (2004), An Introduction to the Study of Medieval Latin Versification. Washington, D. C., Catholic University of America Press. [Obra traducida por Jan Ziolkowski del original francés Introduction à l'étude de la versification latine médiévale, Stockholm, Almqvist \& Wiksell, 1958].

Romera CAstillo, J. (1980), «Poesía figurativa medieval: Vigilán, monje hispanolatino del siglo X, precursor de la poesía concreto-visual», Anuario 1980 de la Sociedad Española de Literatura General y Comparada, Madrid: S.E.L.C.C., 138-156.

Schlunk, H. (1972), «Joseph der Erwählte? zur Problematik christlichen Sarkophagen aus der Bureba», Madrider Mitteilungen 13, 196-210.

SchwaB, M. (1910), «Quatrains judéo-espagnols», Revue Hispanique 23, 321-326.

Stella, F. (1993), La poesia carolingia latina a tema biblico, Spoleto, Centro Italiano di Studi sull'Alto Medioevo.

Stella, F. (2007), Corpus Rhythmorum Musicum Saec. IV-IX. 1. Songs in non-Liturgical Sources / Canti di tradizione non liturgica I. Lyrics / Canzoni, Firenze, SISMEL, Millennio Medievale 72. Acceso web: [http://www.corimu.unisi.it/].

Strecker, K. - Dümmler, E. - Traube, L. - von Winterfeld, P.K.R. (1964-1978), Poetae Latini Aevi Carolini, Munich, Monumenta Germaniae Historica, [1 $\left.{ }^{\mathrm{a}} \mathrm{ed} .1826\right]$.

Uría Maqua, I. (2000), Panorama crítico del mester de clerecía, Madrid, Castalia.

Wilmart, A. (1922), «L'Hymne de Paulin sur Lazare dans un manuscrit d'Autun», Revue Bénédictine 34, 27-45.

ZumThOR, P. (1960), «Un problème d'esthétique médiévale. L'utilisation poétique du bilingüisme», Le Moyen Age 66, 301-335, 561-594. 